\title{
Ovarian pregnancy: an unusual presentation
}

\author{
Ayesha Arif Hussain*, Sultana Aziz, Rina Sharma
}

Department of Obstetrics and Gynaecology, Mayo Institute of Medical Sciences, Barabanki, UP, India

Received: 21 June 2016

Accepted: 09 July 2016

\section{*Correspondence:}

Dr. Ayesha Arif Hussain,

E-mail: drayesha27@gmail.com

Copyright: ( $)$ the author(s), publisher and licensee Medip Academy. This is an open-access article distributed under the terms of the Creative Commons Attribution Non-Commercial License, which permits unrestricted non-commercial use, distribution, and reproduction in any medium, provided the original work is properly cited.

\section{ABSTRACT}

Ovarian pregnancy is a rare type of ectopic pregnancy and usually, it ends with rupture before the end of the first trimester. The clinical picture generally mimics that of ruptured tubal ectopic pregnancy and hemorrhagic ovarian cyst. Transvaginal sonography may be helpful. We report a rare primary ruptured ovarian pregnancy in a 23 years lady.

Keywords: First trimester, Ovarian pregnancy, Partial ovariectomy

\section{INTRODUCTION}

Primary ovarian pregnancy is a rare entity, the diagnosis of which continues to challenge the practicing clinicians. St. Maurice in 1689 reported the first case of ovarian ectopic pregnancy.

Ovarian pregnancy occurs in one in 25,000- 40,000 pregnancies and accounts for $0.3-3.0 \%$ of all ectopic gestation. $^{1,2}$ Of late there has been an increase in the incidence of ovarian pregnancies due to better diagnostic modalities such as transvaginal ultrasonography and wider use of intrauterine contraceptive device (IUCD), ovulatory drugs, assisted reproductive techniques such as in vitro fertilization (IVF), and embryo transfer. ${ }^{3}$

The preoperative diagnosis of this type of pregnancy is not easy. It is characterized by a poor clinical symptomatology and a difficult ultrasound diagnosis. Approximately $75 \%$ terminate in first trimester and are often misdiagnosed as corpus luteum haemorrhage. ${ }^{4}$

\section{CASE REPORT}

A 23 year old, $G_{3} P_{1} L_{1} A_{1}$ with 6 weeks pregnancy, presented to the emergency, with complaints of moderate abdominal pain and spotting for 1day. There was no history of taking any medications. Patient had one emergency cesarean section done 2 years back and a spontaneous abortion at 8 weeks which was followed by dilatation and evacuation, 1year back.

One examination, patient was conscious, oriented, no pallor, with pulse rate of $110 / \mathrm{min}$ and blood pressure of 100/60. Abdominal examination revealed only suprapubic tenderness. On pelvic examination, uterus was anteverted, normal in size, cervical motion tenderness was present. Bogginess was felt in right adnexa along with tenderness in both the fornices.

Urine pregnancy test was positive. Emergency ultrasound revealed. $8 \times 1.4 \mathrm{~cm}$ heterogeneous area with $5 \mathrm{~mm}$ gestational sac within, in the right adnexa. There was free fluid in cul de sac. Uterus was normal in size with ET of $8 \mathrm{~mm}$.

The patient was taken up for emergency laparotomy in view of ruptured ectopic pregnancy. Laparotomy revealed ruptured right ovarian pregnancy with hemoperitoneum (Figure 1,2). Uterus and bilateral tubes were normal. Partial ovariectomy was done and tissue was sent for histopathology. Postoperative period was uneventful and patient was discharged without any complications. 
Histopathology revealed presence of trophoblastic tissue in the ovarian stroma.

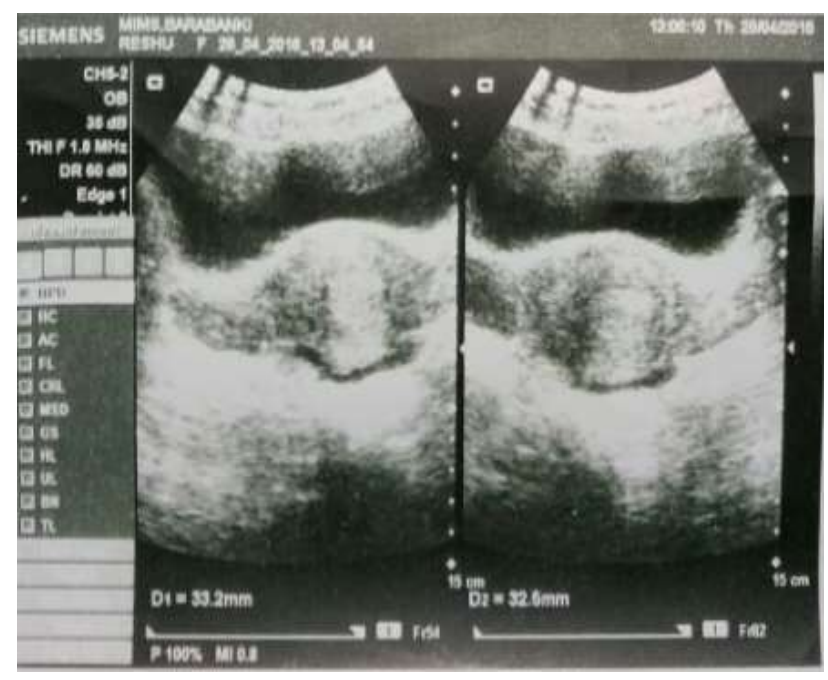

Figure 1: USG showing the empty uterine cavity.

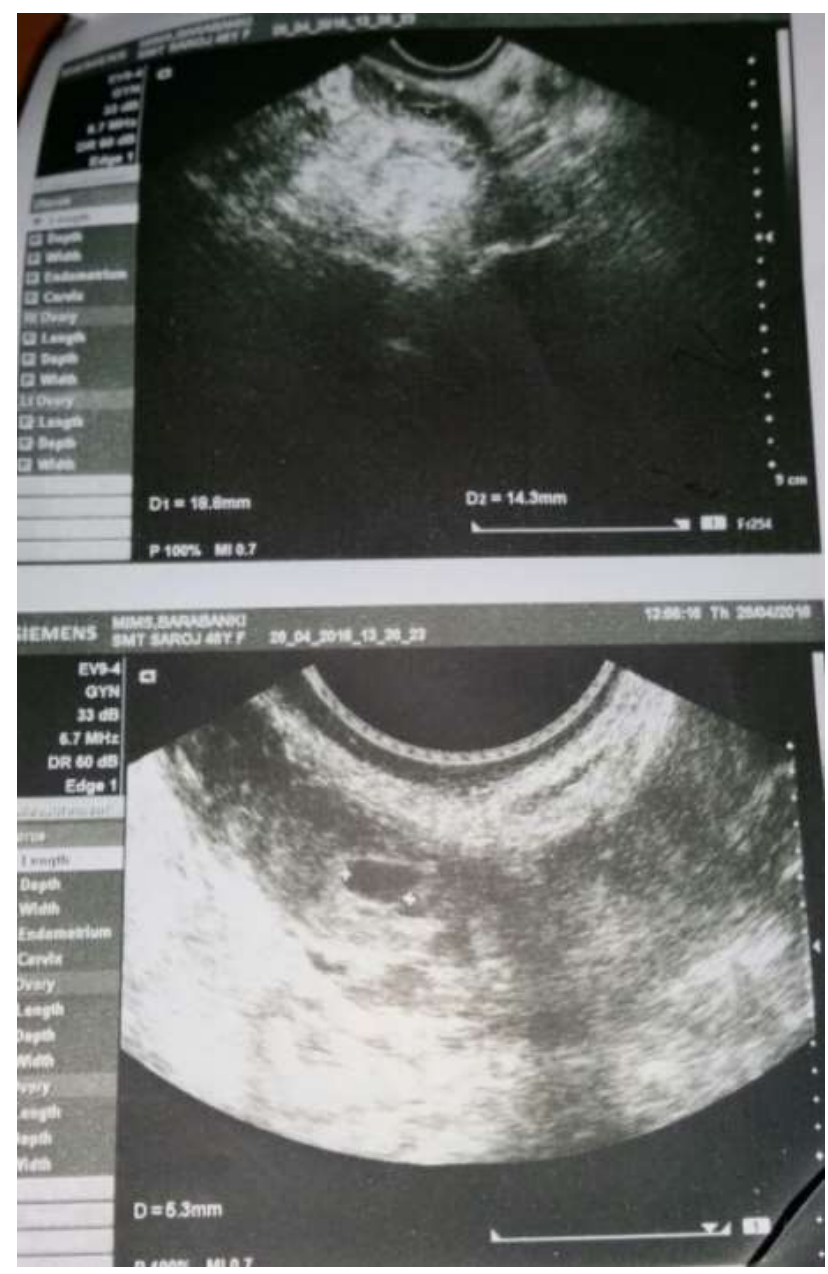

Figure 2: USG showing gestational sac in adnexal region.

\section{DISCUSSION}

Primary ovarian pregnancy is one of the rarest types of extrauterine pregnancy. The signs and symptoms of ovarian pregnancy are similar to tubal pregnancy. Therefore, a differential diagnosis must be considered with tubal pregnancy, ruptured hemorrhagic corpus luteum, or chocolate cyst.

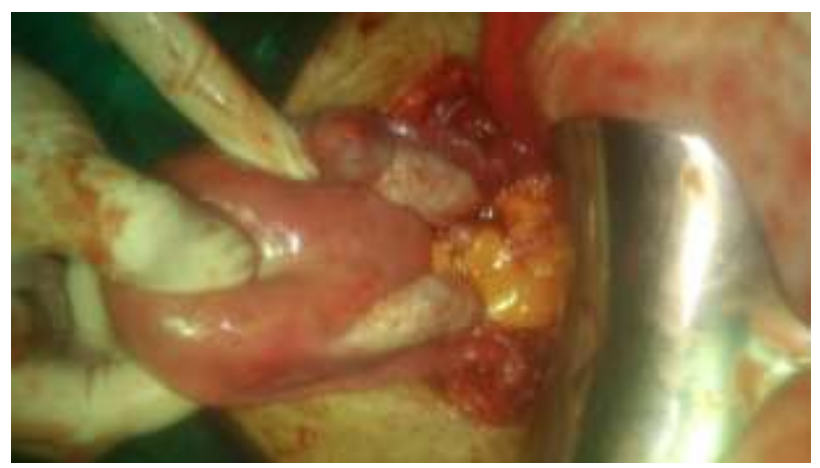

Figure 3: Right ovarian ectopic pregnancy.

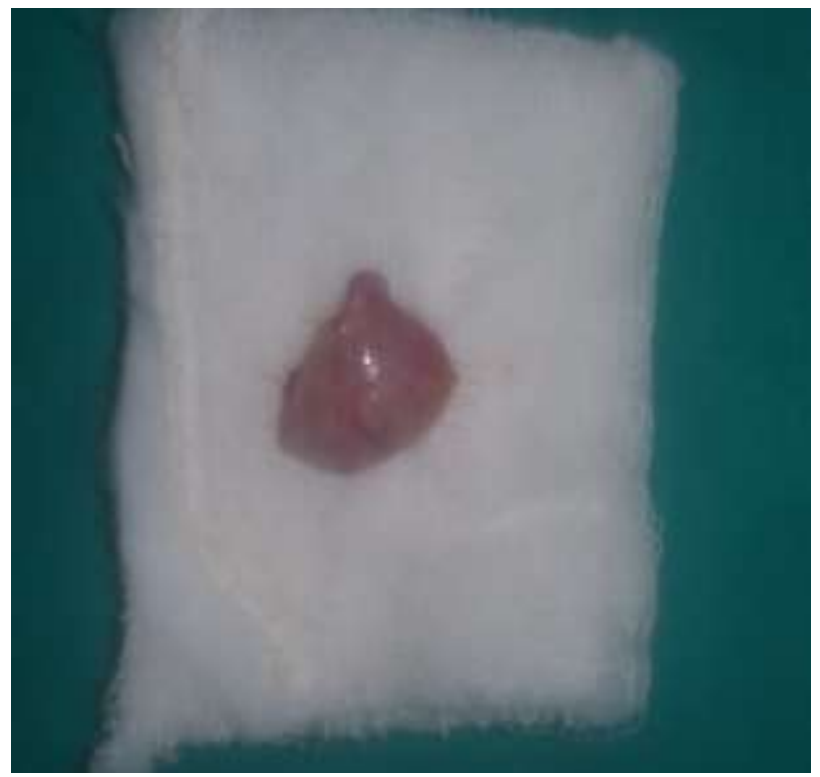

Figure 4: Partial ovariectomy specimen.

With the improvement in ultrasonographic skills and instrumentation, especially with the use of the vaginal probe, a proportion of ovarian pregnancies can be diagnosed preoperatively. Some criteria are very suggestive for sonographic localization of ovarian pregnancy: a wide echogenic ring with an internal echolucent area on the ovarian surface; the presence of ovarian cortex, including corpus luteum or follicles around the mass; and the echogenicity of the ring usually greater than that of the ovary itself. ${ }^{5}$

Spigelberg criteria are historically used for intraoperative diagnosis: intact fallopian tube on the affected side, fetal sac must occupy the position of the ovary on the affected 
side, ovary connected to the uterus by ovarian ligament; ovarian tissue must be located in the sac wall, which is confirmed by histopathology. ${ }^{6}$

Treatment of ovarian pregnancy is mainly surgical ranging from partial ovariectomy to salphingo oophorectomy. Several conservative surgical techniques have been described like ovarian wedge resection for ovarian pregnancy, ovarian pregnancy enucleation, corpus luteum cystectomy for the trophoblast, trophoblast curettage with coagulation or haemostatic suture of the bed of ovarian pregnancy with total conservation of the ovary. $^{7}$

Majority of the patients are young, conservative surgery is generally preferred, as in our case. ${ }^{7-10}$

\section{CONCLUSION}

Diagnosis of ovarian pregnancy is difficult. High clinical suspicion and transvaginal ultrasonography helps in early diagnosis. Its management remains surgical therapy despite the progress in medical treatment. Ovarian wedge resection or partial ovariectomy helps to preserve patient's fertility.

Funding: No funding sources Conflict of interest: None declared

Ethical approval: Not required

\section{REFERENCES}

1. Hertig AT. Discussion of Gerin-Lojoie L. Ovarian pregnancy. Am J Obstet and Gynecol. 1951;62:920.
2. Salas Valien JS, Reyero Alvarez MP, Gonzalez Moran MA, Garcia Merayo M, Nieves Diez C. Ectopic ovarian pregnancy. An Med Intern. 1995;12:192-4.

3. Das S, Kalyani R, Lakshmi V, Harendra Kumar M L. Ovarian pregnancy. Indian J Pathol Microbiol. 2008;51:37-8.

4. Hallatt JG. Primary ovarian pregnancy: a report of twenty-five cases. Am J Obstet Gynecol. 1982;143:55-60.

5. Ghi T, Banfi A, Marconi R. Three dimensional sonographic diagnosis of ovarian pregnancy. Ultrasound Obstet Gynecol. 2005;26:102-4.

6. Spigelberg O. Casusistik der ovarialschwangerschaft. Arch Gynecol. 1878;13:73.

7. Scutiero G, Di Gioia P, Spada A, Greco P. Primary ovarian pregnancy and its management. JSLS. 2012;16(3):492-4.

8. Shrestha A, Chawla CD, Shrestha RM. Ruptured primary ovarian pregnancy: a rare case report. Kathmandu Univ Med J. 2012;10(39):76-7.

9. Goyal LD, Tondon R, Goel P, Sehgal A. Ovarian ectopic pregnancy: A 10 years' experience and review of literature. Iran $\mathrm{J}$ Reprod Med. 2014;12:825-30.

10. Thapa M, Rawal S, Jha R, Singh M. Ovarian Pregnancy-A Rare Ectopic Pregnancy. Journal of Nepal Medical Association. 2010;49(177).

Cite this article as: Hussain AA, Aziz S, Sharma R. Ovarian pregnancy: an unusual presentation. Int $\mathbf{J}$ Reprod Contracept Obstet Gynecol 2016;5:2888-90. 